\title{
ASPECTOS EDUCACIONAIS DO ENSINO DA FILOSOFIA.
}

Peter Büttner - UFMT

peterfil@terra.com.br

O meu professor de redação ensinou, já mais de cinqüenta anos atrás, que é bobagem começar redações lá com Adão e Eva. Evidentemente queria dizer que não é razoável buscar os motivos da introdução muito longe. Apesar deste ensino eficaz, pois até hoje está gravada em mim, vou começar a falar sobre a origem dos aspectos educacionais já bem antes de Adão e Eva. É do momento histórico, cerca de 3,5 bilhões de anos atrás, em que a alga Zyanophyzee aprendeu a distinguir, conhecer e escolher os elementos energéticos do seu mundo exterior, a água do mar. Para estas primeiras atividades meramente biológicas da vida não temos outros verbos a não ser estes das categorias do pensar e conhecer que se encontram em nossa própria natureza e determinam, desde o início da vida, a relação entre o organismo vivo e seu mundo exterior.

Por esta e mais outras razões, defendo que o processo do conhecimento $e$ da vida - incluídos percepção e sentimento, emoção e comportamento - não são estruturas fixas e separadas, mas um único e idêntico processo permanente $e$ aberto de autogera-ção e autosustento, adaptação, aprendizagem e produção de um mundo. Nas teorias dos cientistas contemporâneos, tais como Maturana, Varela, Ditfurth e Capra, encontrei a confirmação desta concepção. Temos de ter presente, não obstante, que com a conquista da autonomia do pensar e criar pela espécie humana, no longo decorrer da evolução, este processo não é mais meramente natural, mas natural-cultural e por meio de sua situação natural-cultural o ser humano se fez a si mesmo gerente da evolução. Com isso o tempo dos acasos terminou. Agora os humanos devem decidir, eles mesmos, como sobreviver, como viver e conviver, conhecendo e respeitando mais e mais as leis $e$ a lógica do universo. 
Assim, com este potencial e com esta necessidade de pensar por si mesmo, o homem, em toda sua história, produziu saberes e concepções de mundo. Muitos dos conhecimentos que construiu foram reformulados, ampliados $e$ muitas vezes superados, para estarem de acordo com a vida, justamente porque viver e conhecer são o mesmo processo permanente e aberto de autogeração $e$ autosustento, adaptação, aprendizagem e produção de um mundo.

Sabemos, não obstante, que o saber e agir humanos não estão sempre de acordo com a vida. A liberdade humana pode escolher aquilo que é contra a vida. E mais: O maravilhoso potencial intelectual com que nasce o ser humano só se desenvolve e capacita, em analogia a uma semente, quando plantado na terra fértil e úmida de um ambiente educacional que propicia e instiga o desenvolvimento de suas habilidades e competências de aprender e pensar, conhecer e criar com sensibilidade ao contexto, em fim, de viver com competência, dignidade $e$ plenitude humana.

Educar, portanto, deveria significar instigar e promover o desenvolvimento indispensável das habilidades e competências cognitivas, criativas e sócio-afetivas, de preferência no diálogo democrático investigativo e reflexivo, interativo $e$ autocorretivo sobre temas transversais e específicos relevantes. A experiência demonstra que assim os educandos se capacitam para conquistar saberes $e$ procedimentos necessários para um mundo em que se pode viver dignamente e feliz e compartilhar uma sociedade com estas mesmas qualidades.

Qual a disciplina que por sua própria natureza procura educar assim?

A disciplina é a Filosofia, mas apenas quando praticada como acabo de explica-lo, isto é, quando cultivada e vivenciada como educação do pensar críticocriativo-cuidadoso. Melhor seria que a Filosofia assim compreendida não fosse uma disciplina separada das demais, mas uma mentalidade, metodologia e atitude em todas as disciplinas, pois, temos apenas um processo de vida e, portanto, só um processo do conhecimento. Vale evidenciar que neste processo bom senso é tão importante como conhecimento e a felicidade acompanha a quem age com bons pensamentos, com boas razões, pois o pensamento faz o ser humano. 
Se é assim, as escolas não deveriam ter como atividade principal o fortaleci-mento do pensar, em vez de deixa-lo apenas como conseqüência casual e eventual?

Com isso tocamos de cheio no aspecto educacional principal da formação filosófica. Estou dizendo formação filosófica, pois ela é muito mais do que apenas ensino. Sem posicionar-me contra a Filosofia como disciplina, pretendo falar aqui mais sobre a visão da atitude do filosofar em contexto da formação humana que hoje em dia e no futuro necessitamos e, falando desta, quero evidenciar alguns dos aspectos deste filosofar formativo. Perguntamo-nos, então:

Qual o tipo de educação, ou melhor, tipo de formação, que necessitamos para isso ? Quais os princípios necessários para esta educação?

Em busca dum novo paradigma para a educação se evidenciaram diversos princípios que devem ser respeitadas na construção deste paradigma, seja em termos de mentalidade pedagógica, seja em termos de metodologia e didática. Esta educação envolve o filosofar como atitude do pensar inteligente e da ação competente.

Evidentemente, apenas esta disciplina não pode constituir o currículo dum programa ou dum paradigma de Educação. Fazendo uma analogia com a panificação, podemos comparar as diversas disciplinas necessárias com diversos tipos de farinha e grãos, com água, leite e gorduras, com o sal e os temperos. $\mathrm{O}$ filosofar seria o fermento que faz toda esta massa crescer e a transforma em pão verdadeiro, isto é, uma formação holística com uma boa compreensão do mundo e o desenvolvimento adequado das habilidades humanas para sentir, pensar, criar, querer e agir com a necessária eficiência.

Exponho aqui algumas reflexões que não são somente resultado do meu esforço individual, mas do trabalho dialógico da comunidade de investigação da minha equipe de pesquisa na UFMT que desde 1992 se constitui com o nome PROPHIL como programa integrado de pesquisa e formação de professores na área da Educação para o Pensar. As sugestóes seguintes, como todo este trabalho, 
não pretendem ser mais do que bases para um diálogo que avança na construção dialética deste assunto.

1- A novas buscas em educação se impõe a necessidade de delimitar princípios e finalidades da Educação: precisamos de uma mentalidade filosófica na escola, a qual cria e desenvolve um processo educativo integral, uma formação, em contraposição à filosofia como uma discipli-na salvadora. Não se trata, portanto, somente de mais uma disciplina, mas sim, de resgatar a atitude filosófica formativa em todas as disciplinas.

Antes de tudo precisamos ter claro o que definimos por ensino eficiente ou sa-tisfatório, ou melhor, o que desejamos quando elegemos os conteúdos e os processos pedagógicos que compõem a grade curricular. Se não nos perguntarmos que tipo de educação precisamos promover e qual sua intenção máxima, não teremos a menor condição de legitimar a inclusão ou exclusão de qualquer disciplina em qualquer cur-rículo, - entre elas a filosofia.

Segue que a primeira questão a ser proposta, reside em uma delimitação de princípios e finalidades, fundados sobre o questionamento: que tipo de educação pre-cisamos e qual o ideal norteador de nossa pratica educacional $e$ formativa?

2- Em lugar da educação tradicional que somente se preocupa em produzir pessoas com grande quantidade de conteúdos e a maior racionalidade possível, a nova proposta vai em direção à educação formativa $e$ plena: o desenvolvimento das habilidades cognitivo-investigativas necessárias para o raciocínio razoável, crítico-criativo-cuidadoso, o metapensamento e o exercício consciente, participativo e competente da cidadania e democracia. 
É preciso educar nossas crianças no intuito de torna-las cidadãos de bem, bons profissionais, boas pessoas, gente feliz. Devemos prepara-las para desempenhar os infindáveis papeis sociais de maneira eticamente adequada, competente e critica, conscientes de sua individualidade e de sua sociabilidade.

Podemos dizer que pretendemos uma formação, mediatizadora de todas as funções sociais por nos vivenciadas, que promova a aquisição da cultura e que ao mesmo tempo reflita sobre ela e lhe faça a crítica necessária - uma formação promo-vedora do homem, possibilitando a nossas crianças a autopercepção de seres que se distinguem de todo o resto, embora totalmente integrados nele, senhoras de seus próprios caminhos, personalidades livres em suas deliberações $e$ produções, responsáveis por suas ações e capacitados e prevenidos para solucionar as dificuldades da vida, embora muitas vezes imprevisíveis,

3- Segundo correntes contemporâneas da biologia, etologia, neurociência, psicologia e outras, a humanidade não usa plenamente as potencialidades do telencéfalo, tendo por conseqüência o desenvolvimento de uma racionalidade limitada $e$ limitadora, portanto, parcial $e$ insuficiente à solução das problemáticas humanas, tanto para desenvolver as habilidades mais eficientes do telencéfalo, potencialmente já existentes, quanto para o seu aprimoramento em termos de evolução, precisamos de uma educação que desenvolve as habilidades do raciocínio $e$ do metaraciocínio.

Se partirmos da premissa que o homem é racional - racionalidade como capa-cidade de produzir com autonomia e criatividade conhecimentos intersubjetivos pela troca de aprendizagens e reflexões, sempre os modificando em função de novas situa-ções vivenciais $e$ intenções peculiares -, agente criador $e$ transformador do meio e de si mesmo, realizando esses processos no mais das vezes coletivamente, podemos arriscar que a educação que precisamos $e$ 
pretendemos é aquela que promova e desenvolva as habilidades para estas características, tornando-as conscientes e potencializadas até a sua excelência, e ainda, que as promova de maneira conjunta e consorciada.

Carecemos de uma educação a qual, mais que transmitir conhecimentos por descrição e acumulação, abarque condições para o eficiente pensar, investigar e refletir sobre a cultura já produzida e abra as fronteiras para a pesquisa e a criação em todas as áreas da atividade humana, fornecendo ferramentas afiadas e subsídios para a solução dos problemas que emergem das inúmeras situações onde as ações, os novos conhe-cimentos e as crenças anteriormente aceitas, se chocam $e$ interagem. É esta a formação que devemos conceber, criar e promover.

4- $\quad$ A Filosofia para Crianças - Educação para o Pensar de Matthew Lipman que converte a sala de aula em comunidade de investigaçáo, através de um trabalho autodirigido $e$ autocorretiva, coletivo $e$ interativo, sistematizador do desenvolvimento das habilidades cognitivo-criativas $e$ sócio-afetivas $e$ da produção $e$ reprodução de saberes em lugar do tradicional ensino dirigido, individualista $e$ apenas receptor passivo, pode ser considerado um protótipo pioneiro para o paradigma que buscamos.

É sob esta perspectiva que a filosofia, como atitude, adquire teor e função pedagógicos ao ser inserida no ensino fundamental e médio, como disciplina engendra-dora do desenvolvimento pleno das potencialidades humanas com vistas a sua raciona-lização, conscientização e totalização eficazes. Jamais pode ser instrumento doutrinário e doutrinador ideológico, nem puro exercício retórico, procedimentos que descreden-ciam o que há de mais genuíno e singular no filosofar.

As aulas de filosofia em pauta não significam também recitar conceitos e historiografia filosófica; o que se realiza está deveras distante desse procedimento. Este filosofar nas salas de aula está organizado no sentido de trazer para os alunos 
um mo-delo instigador da investigação filosófico-científica e mais especificamente a maieútica socrática, onde os participantes de um diálogo são fecundados para dar à luz idéias e conhecimentos a partir de si mesmos. É o que o Prof. Matthew Lipman denomina comunidade de investigação, querendo dizer que a comunidade de sala de aula tem de tornar-se reflexiva e perseverante na exploração autocorretiva de questões conside-radas, ao mesmo tempo, importantes $e$ problemáticas. (Lipman, M. A Filosofia vai à Escola, Summus Editorial, São Paulo 1990, p. 37).

O espírito e a prática de partejar idéias pela conversação comunitária, instigada, organizada, ordenada e construtiva podem ser disseminados entre todas as disciplinas, tornando-as ricas e interessantes, espaço em que os próprios alunos tornam-se agentes do conhecimento e não meros receptáculos.

5- Educação não é apenas descrição, transmissão e memorização de conteúdos. Não é mera instrução de fora para dentro do aluno. É o propiciar e instigar do autodesenvolvimento do potencial dentro do aluno, de sua capacitação e exteriorização eficazes e eficientes. $O$ ensino, como busca dos conhecimentos já produzidos, se torna assim re-construção vivencial e crítica num processo ativo e participante da produção do conhecimento contextualizado, individual e coletivo.

A filosofia, contudo, não se legitima apenas como instrumental. A investigação filosófica proporciona o pensar rigoroso, investigador, contextualizante e aberto que antecede qualquer conhecimento, desde que o processo de conhecer não signifique apenas descrição e memorização de conteúdos.

O filosofar, portanto, não é uma mera disciplina curricular, mas sobretudo, uma competência e atitude em todas as disciplinas, em todo sentir, pensar, investigar, querer $e$ agir do ser humano diante a realidade que por meio desse filosofar se torna co-nhecimento. É preciso, então, restituir a dimensão filosófica à educação, da qual vem sendo destituída pela sua formalização e tecnicização, 
fragmentação e descontextuali-zação, tanto como pela capacitação precária da maioria dos profissionais da educação e das respectivas políticas. A filosofia como educação para o pensar, em nossa situação atual da educação, pode ser uma disciplina emergencial com a função de fermentar com sua atitude e suas habilidades toda a educação, tanto em termos de mentalidade e prática, quanto em pessoas docentes e discentes. Sendo isto alcançado, todas as disci-plinas terão função e efeito igual ou semelhante a ela. É isto também o caminho para uma formação holística que, evidentemente, não pode ser somente da responsabilidade da filosofia.

Isto, contudo, não quer dizer que a filosofia um dia poderia ser eliminada. Ao entendermos o conhecimento como um processo que induz a compreensão de um conteúdo, de sua elaboração, de sua linguagem peculiar e de sua finalidade, e que todos estes elementos não impliquem em uma verdade acabada, a filosofia se coloca como instrumento mais que adequado para viabilizar o conhecimento, pois através dela as coordenadas éticas, lógicas, epistemológicas, estéticas etc., de todas as disciplinas, são contextualizadas e historiadas. Ao sugerir o percurso pelo qual as várias áreas do conhecimento foram e são pensadas, e ao fazê-lo ao modo próprio do filosofar, ou seja, pela problematização, dúvida e rigor lógico-reflexivos, todo e qualquer conteúdo avança e adquire significado, não sendo apenas um dado que não serve para nada, sem compreensão de sua origem, de sua causa e efeito, de seu sentido e de sua finalidade e que nem provoca, nem manifesta qualquer interesse.

A investigação filosófica recupera os valores das incertezas necessárias ao mo-vimento de dar sentido as coisas, permite explorar suas possibilidades e conduzi-las, desde que devidamente encaminhadas, a um significado pertinente, a um conhecimento que nasce e cresce a partir do próprio objeto de estudo; resumindo: permite pensar a disciplina em sua própria linguagem. 


\section{6- Necessitamos avançar ao metaraciocínio, partindo do raciocínio. Para esta tarefa precisa-se desenvolver ao máximo e conjuntamente as habilidades do raciocínio.}

O pensar filosófico-científico assume ainda uma conotação bem mais ampla que a simples apresentação de conteúdos e a solução de exercícios. Significa compreen-der linguagens (a linguagem matemática, a linguagem geográfica etc.) desenvolver habilidades indispensáveis a qualquer produção cientifica, Ética, Política, Estética etc., implica em ter condições de eleger critérios de avaliação, fazer inferências, ordenar logicamente, formular perguntas, desenvolver conceitos e para além disso, poder com-preender o próprio processo do pensamento e do conhecimento, realizando um meta-pensamento, compreendendo o processo que leva à duvida, à imaginação, às inferên-cias, pensar o pensar e tomar consciência da intersubjetividade que ai está se processando e, sobre tudo, questionar sempre de novo não somente este processo, mas também os produtos do pensar filosófico-científico a respeito de sua validade $e$ eficácia, tendo como referencial a qualidade de vida do gênero humano como um todo. É isto que chamamos de metaraciocínio ou metapensamento.

Principalmente pelo metaraciocínio, que precisamos desenvolver, evitaremos também que as nossas crianças se transformem em gênios ou máquinas pensantes. O procedimento filosófico com certeza de nada nos valeria, se isto fosse o caso.

O que precisamos é criar em sala de aula mentalidade e postura investigadoras e criativas a tudo que nos rodeia e gerar um diálogo metodologicamente conduzido, tornando os conteúdos escolares muito mais interessantes e significativos, vivenciais e, porque não, divertidos e lúdicos. $\mathrm{O}$ alvo principal, contudo, não são os assuntos, mas as habilidades de pensar, pesquisar, criar e dialogar. Os assuntos mudam a toda hora e caducam rapidamente, as habilidades continuam com a mesma eficiência no meio dum mundo em transformação. 
7- O processo do desenvolvimento das habilidades do pensar inteligente, partindo das experiências vividas pelos alunos e refletidas e discutidas por estes, pode propiciar a superação dos tradicionais currículos fragmentados objetivando um currículo orgânico, no qual os conhecimentos estão integrados interdisciplinarmente, dentro de uma visão totalizante.

A condição para isso é a formação do professor para este processo a fim de poder realiza-lo em comunidade de investigação competentemente, pois meras imitações técnicas são insuficientes. Principalmente, para sua aprendizagem inicial, precisa-se de livros didáticos à semelhança daqueles que o professor Matthew Lipman escreveu para os seus alunos. Não quero dizer que sejam os únicos possíveis. No mercado brasileiro já existem obras didáticas que nasceram da mesma mentalidade e comungam do mesmo paradigma. Na nossa experiência com professores recém-formados, que se manifestaram convictos de poder realizar o mesmo trabalho com qualquer outro texto e sem vestir a camisa deste paradigma filosófico-pedagógico, verificamos que, mesmo em aulas interessantes e bem dialogadas, o professor não conseguiu trabalhar tantos conceitos básicos relevantes em certo contexto, com certa seqüência e com a mesma profundidade. Mais grave, contudo, mostrou-se um menor desenvolvimento das habilidades cognitivas nas crianças. Duma maneira geral pode-se afirmar, que os romances filosóficos de Lipman podem garantir uma aprendizagem melhor do método, e mesmo uma série de conceitos, de idéias e teorias, por parte do próprio professor; por parte do aluno, um embasamento mais organizado e mais rico. Com isso não quero apresentar a obra de Lipman como a única possível. Meu intuito é alertar que um professor sem o devido preparo filosófico e didático, com muita dificuldade vai alcançar o objetivo com qualquer material não organizado para isso. $\mathrm{O}$ uso adequado desse material, por sua vez, capacita mais e mais o professor.

O professor Lipman caracteriza os seus livros do programa Filosofia para Crianças da seguinte maneira: 
"O texto tradicional dá lugar ao romance filosófico, um trabalho de ficção, constituído, tanto quanto possível, de diálogos de modo a eliminar a repreensível voz de um narrador adulto atrás dos bastidores. As idéias filosóficas estão espalhadas profusamente em cada pagina, de modo que é raro que a criança possa ler uma pagina sem ser golpeada por alguma coisa intrigante, alguma controversa ou algo que a deixe maravilhada. À medida que as crianças que povoam o romance vão se envolvendo numa cooperação intelectual e, assim, formando uma comunidade de investigação, a história se torna um paradigma para as crianças reais da sala de aula. De fato, o objetivo de cada um desses romances é ser um exemplo ao retratar crianças de ficção no ato de descobrir a natureza da disciplina na qual e sobre a qual é esperado que as crianças da sala de aula pensem." (Lipman, M. A Filosofia vai a Escola. Ed. Summus, p. 22)

O romance filosófico, em sentido figurado, corresponde a uma semente. Cultivada pelas crianças, ela ultrapassa a si mesma e se desenvolve à árvore, pratica-mente ilimitada. Brotos, galhos, folhas, flores e frutas nascem com muita criatividade de investigações, reflexões, comparações, conclusões, definições e concepções, com raciocínios válidos, argumentos criteriosos e juízos críticos. As habilidades que as crianças adquirem com esse método, ao contrario de conteúdos adquiridos no pacote pronto, caducos dentro de pouco tempo, continuam, e ainda se aguçam, no meio dum mundo em transformação.

Com o decorrer das atividades em comunidade de investigação, usando os romances ou novelas de Lipman, tanto os professores, como os alunos, podem adquirir a capacidade para produzir histórias próprias com o mesmo valor instigador e gerador do processo de conhecimento e do desenvolvimento de habilidades. Este, propriamente, é a relevância destas histórias, bem como a conseqüente reflexão e discussão das experiências vividas. O intuito é superar os tradicionais currículos fragmentário. Como resultado, espera-se um currículo orgânico, no qual os conhecimentos estão integrados, dentro de uma visão totalizante do mundo e da vida. De preferência, isto deve ser feito em nível interdisciplinar, transversal e interescolar. 
Como disciplina a Filosofia para Crianças - como protótipo da educação para o pensar - age com as funções de núcleo orgânico, metódico e globalizante, do processo de produção do conhecimento. Assume também a função integralizadora, quando seu conteúdo programático estiver coordenado com os das demais disciplinas oferecidas. Desta maneira, o currículo como um todo consegue suprir lacunas entre as etapas do processo de conhecer, sem a característica dos currículos fragmentados, com disciplinas despidas de seus pressupostos filosóficocientíficos, apresentadas como verdades dogmáticas e desligadas de sua historia. A filosofia com o papel de educação para o pensar inteligente tende a reduzir essa fragmentação no currículo ao desenvolver as preocupações filosóficas inerentes às disciplinas, catalisando-as e integrando-as em sua variedade pela recuperação de sua historicidade, de sua linguagem e de sua legitimação, tornando-as vivas $e$ significativas.

Como modelo de investigação, ou seja, como perseverança na exploração auto-corretiva de questões consideradas, ao mesmo tempo, importantes $e$ problemáticas, o filosofar estaria presente nas demais disciplinas. Exigiria, em conseqüência, o compromisso dos alunos e professores, que também nestas pratiquem a comunidade de investigação, em que o dialogo orientado entre eles, na discussão de idéias, possa converter-se em conhecimento e exercício de habilidades cognitivas e vivenciais.

8- Pelo processo do desenvolvimento das habilidades do pensar inteligente no "ensino" adequado da filosofia - com a conquista da autonomia do pensar, querer, agir e criar, da competência de criar significados, de buscar boas razóes, de agir de acordo com uma lógica prática e ética - se desenvolve outro aspecto humano que se alcance apenas pela educaçãoformação: o agir competente. 
A tarefa maior da formação humana é a capacitação do educando para o pensar e agir autônomos, o que quer dizer: Instigar e orientar a individualidade à competência de autonomia, sem a qual, hoje em dia, a vivência humana é impossível, seja em termos de convivência social, seja do viver pessoal digno, feliz e competente, sempre em relação com as condições, possibilidades e formas da realidade social.

Dado que a capacidade de orientação dos seres humanos, em nosso tempo, ultrapassou os limites de suas possibilidades, podemos constatar a incapacidade de orientação da maioria e a necessidade correspondente de orientação. Esta impotência de orientação se originou dos seguintes fatos:

A complexidade cada vez maior do mundo vivencial de cada um, junto com as conexões múltiplas dos conhecimentos científicos para este mundo individual $e$

- a multiplicidade das visões concorrentes da vida e do mundo, com a

- pluralidade das culturas e etnias, éticas e moralidades, significações, valores e normas, com

a extrema especialização das ciências e as responsabilidades no dia-a-dia da profissão e da vida em geral, e last but non least com

a perda da cultura lingüística interdisciplinar das ciências com o aumento de linguagens altamente especializadas e impossíveis de serem unificadas, com

- a perda de uma cultura lingüística universalmente praticada e a deficiência de uma base comum de comunicação em forma de um idioma qualificado para isso. (LÖWISCH, 2000, 4) 
A questão "o que devo fazer?" está ligada a esta impotência de orientação para decisões e ações autônomas. O indivíduo, pela incerteza de seus valores $e$ significados, fica impossibilitado de determinar-se a si mesmo responsavelmente em situações decisi-vas. Mais e mais se sente incompetente. Assim, delega sua competência de ação a especialistas, à sociedade, ao governo, à ciência, a funcionários capacitados e, com isso, se desfaz de sua autonomia no pensar e agir. Dado que lhe falta qualquer possibilidade de controlar esta delegação de sua competência de ação a terceiros, se torna dependente destes e com isso impotente.

A busca de causadores e culpados desta situação não leva a nada. Precisamos duma educação que prioritariamente propicia a formação da competência de ação dos educandos com base na tradição, na situação atual da ciência, técnica, sociedade e política e com prospecção do futuro. Esta competência de ação não deve ser confundida com competências de ação científico-instrumental, técnica e tecnológica. Estas com-petências se ensina pela instrução, pelo treinamento e por ações pedagógicas. A competência de ação é meta da formação humana e deve ser compreendida como competência de ação pessoal. A fim de compreender bem a grande diferença entre educação-ensino $e$ educação-formação quero explicitar sucintamente as características de cada uma.

A educação-ensino é toda ação pedagógica - profissional ou não - no sentido de procedimento de influência direta ou indireta sobre o educando. Objetivos, entre outros, são ensinamentos de limpeza e higiene, mediação e transmissão de costumes da família e das virtudes secundárias de comportamento correto, pontualidade, delicadeza, decência, tanto como na área socializante a mediação de normas, sua observação e a aplicação de sanções e, na área cultural e científica, a transmissão das matérias dos currículos escolares de todos os níveis. A determinação dos objetivos, o planejamento metódico, a consideração do desenvolvimento psicológico do aluno, a maneira adequa-da de falar com ele, a crítica do procedimento e o controle do sucesso sempre estão na mão do educador É o educador que faz da criança, ainda crua e nua, anti-social, sem cultura $e$ disciplina, incapaz de sobreviver sem ajuda de outros, um membro útil da sociedade, capaz de contribuir para esta e de conviver nela. Ele entrega à 
sociedade os sócios preparados para reproduzir a sociedade, ajustados e adaptados às regras sociais, às convenções, às regularidades e normalidades, submissos às estruturas normativas, à culturação e enculturação ou, pelo menos, influenciados por estas. O educador, trabalhando com respectivos métodos educacionais $e$ intencionando o alcance de determinadas metas por meio de sua influência, se caracteriza como fazedor direto ou indireto da educação do aluno, independentemente de qualquer procedimento que possa instigar e conquistar o educando para ser parceiro ativo do processo da educação. A mentalidade do procedimento educacional é de guia de estranhos com meta determi-nada e medidas disciplinares rigorosas. O método principal é influência do educador sobre o educando. Estes papeis são irreversíveis. A meta é a produção de uma situação externa do educando.

A pedagogia considera a educação-formação como ação pedagógica comple-mentar à educação-ensino. Formação é analiticamente diferente de ensino, mas na ação pedagógica inseparável do ensino, contando que este é a condição prévia de formação. Na área da formação, o papel dos atores é reversível, o que é o específico da formação.

Recorro ao filosofar com crianças, como tarefa de formação, para evidenciar o que significa esta troca do papel dos atores: no discurso filosófico com crianças o educador não é o condutor e guia de estranhos como no ensino. As crianças devem aprender assumir o papel de atores ativos através do filosofar com elas, por meio do questionamento investigativo $e$ da aprendizagem da argumentação e da discussão ordenada e interativa, democrática e autocorretiva. Devem aprender com isso a formar-se a si mesmas, começando com pequenos $e$ mínimos passos. O pedagogo age como provocador do pensar, instiga com perguntas intrigantes a fim de estimular e capacitar os formandos para pensar por si mesmos. Filosofar com crianças, no sentido de reflexão e diálogo comunitários, não quer dizer refletir e dialogar sobre pensamentos da tradição filosófica, mas significa pensar por si mesmo sobre problemas, fenômenos, situações $e$ circunstancias, sobre dúvidas e experiências que provocam curiosidade, admiração ou espanto. Este pensar procura descobrir as causas do ser das coisas e por que 
provocam curiosidade, busca que significado e relevância possuem, qual valor lhes pode ser atribuído, qual a responsabilidade que temos para com elas, quais as assim chamadas questões últimas do ser humano e como podem ser assumidos, o que podemos saber sobre a nossa personalidade, nossa individualidade $e$ identidade e o que elas significam.

Os temas de reflexão e diálogo são formulados pelos alunos, sujeitos ativos do processo, e sempre diante e dentro de seus mundos de vivência. Por causa das contingências do mundo de cada um, de suas biografias e situações de vida longe de objetividade, são quase sempre subjetivos e, como estes também os resultados do pensar são sempre ligados a determinada subjetividade.

Diferenciando-se do ensino, no qual se trata de exigências objetivas, onde sucesso e insucesso são controláveis e comprováveis, em que os métodos e seu alcance podem ser criticados e efetivados, a formação humana está ligada $e$ dependente da subjetividade e personalidade dos educandos. O que o indivíduo seja criança, jovem, adulto - faz do processo formativo, instigado pelo educador, é iniciativa e criatividade dele como ser autoformante, sendo consciente disso ou não. $\mathrm{O}$ ator responsável no processo de formação é o próprio autoformante, não mais - como no ensino - o professor. O andamento da formação de cada um não está mais nas mãos do pedagogo Com isso o jeito desse processo se revela como autocondução de quem está se formando a si mesmo, condicionado e possibilitado pelo seu potencial racional e sob princípios da razão e razoabilidade que podem ser chamados, também, de idéias reguladoras da razão. O método do professor, que de certa maneira está moderando este processo formativo, consiste em instigar, propiciar e auxiliar a capacitação do aluno para a sua auto-capacitação. Esta acontece pela aprendizagem do pensar por si mesmo pedagogicamente engendrada e acompanhada, dependendo da aptidão do educando para pensar por si mesmo.

Dado que neste processo formativo não se trata de uma meta metodicamente planejada e alcançável pelo uso de meios reforçantes $e$ 
sancionantes - como no ensino -, mas da capacitação para pensar e agir por si mesmo, não se pode falar em meta da formação. Mais adequado é falar em tarefas de formação que correspondem à disposição interna do autoformante. Esta disposição interna se manifesta na atitude pessoal que o sujeito da formação conquistou, aparece pela autonomia do pensar e agir, pela autodeterminação de acordo com boas rações, saberes relevantes construídos por ele e por uma consciência crítica no manejo com coisas, fatos, fenômenos e seres humanos, com a natureza e bens culturais.

Nosso tema é "Aspectos educacionais do ensino da filosofia". Errei o tema, pois falei de aspectos formativos da educação filosófica. Fiz com plena consciência e prazer, convicto de que a maioria de nós interpreta assim o tema proposto. É, portanto uma questão de terminologia que vale a pena ser esclarecida, tanto em razão da clareza dos conceitos, quanto para conscientizar-se dos aspectos mais importantes, mais elevados, de nosso trabalho na formação humana de crianças, jovens e adultos. Mais do que com a relevância do desenvolvimento das habilidades e competências cognitivas e sócio-afetivas, preocupei-me com uma macrovisão dos aspectos da formação pelo filosofar que resumo assim:

\section{Capacitação do educando para}

1. a emancipação $e$ - pelo desenvolvimento das habilidades cognitivas - para o uso autônomo e competente de seu potencial racional;

2. sua autonomia e independência responsável;

3. sua autodeterminação, sua percepção sensível de co-responsabilidade pessoal autodeterminada e seu agir correspondente;

4. fazer juízos diferenciantes e discernantes sobre fenômenos, fatos e situações;

5. a percepção de valores com sensibilidade de contexto, sua argumentação e crítica, sua escolha; 
6. a reflexão sobre significados e a avaliação de princípios éticos e normas morais;

7. a produção de qualificações refletidas e pessoalmente responsabilizadas;

8. o agir autêntico e sincero;

9. a reflexão sobre a relação de tensão inevitável entre o eu e o mundo, indivíduo e pluralidade de culturas;

10. a reflexão e o juízo sobre conceitos e temas transversais;

11. atitudes e habilidades que favorecem a coragem de defender suas convicções;

12. a consciência de dever e poder vencer situações difíceis por ações competentes e atitudes críticas e responsáveis;

13. a percepção competente de competência que não acontece automaticamente.

Concluindo: O "ensino" (entre aspas) da filosofia, do filosofar com crianças e jovens nos moldes lipmanianos, é formação humana que, diferente do ensino tradicio-nal, capacita para um processo de autodeterminação e autoformação por meio de aprendizagem autodirigida em consonância com o desenvolvimento mental individual. O educando se torna ator da reflexão investigativa crítica e argumentativa sobre tudo aquilo que constitui o mundo com o qual o eu se confronta, o que significa o mundo vivencial do eu. Ao mesmo tempo, esta reflexão se relaciona com aquilo que o ensino está tratando, considerando significados e valores, relevâncias e qualidades. As ações provocantes e coadjuvantes do educador propiciam a capacitação para a autoformação do aluno, orientada pela racionalidade e razoabilidade, desenvolvendo habilidades e atitudes necessárias para vencer tarefas. A ação pedagógica considera o aluno sujeito do processo e pessoa autônoma em busca de significados e qualidades autenticamente humanas, de autodeterminação e 
construção de um centro pessoal de decisões e ações, de negações e aceitações fundamentadas e sem contentar-se com respostas prontas.

Esta educação-formação pretende, também, capacitar para um pensar humanitário, para uma sensibilidade ética e para o uso mais competente e razoável do potencial racional humano e, ligado a isso, para a resistência contra o não razoável, para a ação competente, a co-determinação democrática, a cooperação e solidariedade.

Diante da total falta, em nosso meio, dum sistema de educação-formação, diante da urgência de transformar o ensino de apenas transmissor em produtor de conhecimento, em formação de consciências críticas e pensadores e atores competentes, temos de ter a coragem de dar passos pioneiros para uma educaçãoformação, tanto para o progresso científico, quanto para o viver quotidiano num mundo que hoje depende desta formação para atender à sobrevivência da humanidade, à manutenção da vida no Planeta, ao crescimento qualitativo da cultura e da vida de todos os seres humanos com maior igualdade e justiça, dignidade e felicidade no gozo da paz mundial.

Bibliografia:

BÜTTNER, P. Mutação no Educar. Cuiabá: EdUFMT, 1999.

LIPMAN, M. A Filosofia vai à Escola, São Paulo: Summus Editorial, 1990.

LÖWISCH, D-J. Kompetentes Handeln. Darmstadt: Wiss. Buchgesellschaft, 2000. 